Dr. Galezowski intends, the operation cau scarcely be called a new one, bearing as it does such a close resemblance to a procedure to which M. Perrin lays claim. M. Perrin thus

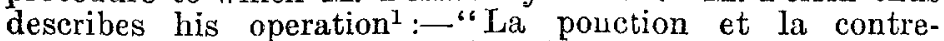
ponction sont faites aux limites de la cornée suivant une ligne passant ì $2 \mathrm{~mm}$. au dessus d'un méridien horizontal. A ce mocur la base de lincision mesure $9 \mathrm{~mm}$, en prenant toujouxs pour type une cornée de $10 \mathrm{~mm}$....... L'incision est ensuite conduite de bas en haut de façou à aboutir 1 ou 2 millimètres au dessus du limbe de la cornée." A com. parison of these two methods of procedure shows that as regards the incisions of the cornea they are almost identical. It is true that M. Perrin usually performed an iridectomy which Galezowsli avoids; still, this departure hardly justifies the assumption of the title of a new operation. A very slight modification in the situation of the incision would again correspond to what I have always understood to be Lebrun's, or the Belgian operation, an operation I have performed for the last eight or nine years in almost all cases of senile cataract, with which $I$ bave every reason to feel satisfied, and which I believe is very commonly performed in England. I am, Sir, yours, \&c.,

Newcastle-on-Tyne, Jan. 22nd, 1883. Surgeon to the Fiye Infirmary.

\section{DILATATION OF THE FEMALE URETHRA.}

\section{To the Eiditor of THE LANCET.}

SIR,-In a clinical lecture on "Calculus in the Female Bladder," published in your valuable issue of Dec. 23rd, 1882, Mr. Heath is accredited with the following words :- "I proceeded to dilate the urethra with a pair of polypus forceps and then introduced my little finger, and subsequently my forefinger, without difficulty. In this rapid dilatation there is, of course, some laceration, and it is usually upwards under the pubes and does no harm" (the italics are mine). This statement, coming from so distinguished a surgeon, is I think, calculated to do much harm, unless properly interpreted. Although so fortunate perhaps as not to have met with a mishap in his own practice, I am sure Mr. Heath does not intend to convey the idea that dilatation of the female urethra carried to the extent of admitting the forefinger and to laceration, does not carry with it more or less danger of permanently impairing the retentive power of the bladder. It is undoubtedly true that the urethra and neck of the bladder is, in some females, susceptible of remarkable dilatation. In an operation for the removal of a soft villous growth from the bladder of a female, Winckle introduced both fingers and forceps into the viscus, the urethral mucous membrane was fissured, and yet none of the 150 grammes of water injected after the operation escaped from the bladder. In a similar operation by Schatz, although the urethra was dilated to an extent admitting two fingers, she could not retain her water one hour after the operation, though she soon regained the full tonicity of her sphincter; but, on the other hand, itis wellknown that this not diffcult operation has been responsible for a great deal of suffering and misery in the protracted, and, in some instances, permanent incontinence of urine which it has occasioned, and rather than inculcate a feeling of safety, the novice should be warned against repeating an accident which has occurred in most experienced hands. That laceration of the urethra occurs, as a matter of course, is not to be wondered at when we consider the rude instruments that are made to serve the purpose of urethral dilators. In order to conform to the conditions by which alone a maximum degree of dilatation, without laceration, can be accomplished, the expansive force of the dilator should be distributed equally over all parts of the circumference of the urethra, by the unrolling of rounded blades, and not upon two or three sides of the canal as effected by the uterine dilators, polypus and bone forceps, so commonly employed. Again, the dilatation must be as gradual as it is continuous and uniform; that is, the degree of force exerted should be carefully regulated to the amount of resistance to be overcome. An instrument providing for the conditions aforesaid is constructed by Tiemann and Co. of this city, and has been used here with great satisfaction for several years. It is both dilator and speculum. When closed it is $39 \mathrm{~mm}$. in circumference and is capable of expansion to $6 \frac{1}{2}$ centimetre. Yours truly, Alex. W. STeIN, M.D.

Surgeon to the Charity Hospital, \&c., New York City.

New York, Jan. Joth, 1883.

1 See a paper by Dr. Warlomont, Annales d'Oculist. tom. 1xxi., p. 15.

\section{THE EFFECT OF TEMPERATURE UPON THE STAINING OF THE BACILLI OF}

\section{TUBERCLE.}

To the Editor of THE LANCET.

SIR,-In one or two of the recent communications to your journal reference has been cursorily made to the influence of temperature upon the staining of the bacilli of tubercle, but sufficient prominence has not, I think, been given to this most important fact. With active staining fluids of the best kinds, and with material rich in bacilli, failure may result as a consequence of the fluids being maintained during the process of staining at too low a temperature. This has been a common experience during the recent cold weather; even the temperature of a moderately warm room at this time of the year is too low to give uniformly good results. I endeavoured at first to obtain the necessary tem. perature by placing the capsules containing the preparations and fluids near the fire upon the hob or hearth, and although many of the results were highly successful, some failed, for it seems to be the case that not only too low a temperature but even too high a temperature, may lead to failure. A water-bath is the apparatus best fitted for the purpose, as the temperature can in this way be easily maintained at about $100^{\circ} \mathrm{F}$. for some hours; or if the expense of a water-bath be too great, an apparatus quite sufficient for the purpose may be made out of an ordinary hot-water dish or tin, upon which the preparations are placed, covered by a tea-cosy or a cap of felt or flannel.

Koch's experiments have shown that the temperature is all-important in the cultivation of these bacilli; and it is interesting to find that the same temperature (about $100^{\circ} \mathrm{F}$.) at which they grow best is also that at which they stain best

I make this communication in the hope of saving others the vexation and lost labour which ignorance of the fact long caused me. I am, Sir, yours truly, SAMUEL WEST, Physician to the Chest Hospital, Victoria Park
Wimpole-street, W., Jan. 8th, 1883 .

To the Editor of THE LANCET.

SIR,-Permit me to add some brief remarks to those which have recently appeared in your columns upon the methods of staining the bacillus of tubercle.

Mr. Prideaux, in THE LANCET of Dec. 30th, 1882, seems to imply that methylene blue, when used as the second stain, does not stain the bacilli of putrefaction; and there. fore he recommends the use of orentian violet for this purpose. In my hands the methylene blue, used as a second stain, does stain the various bacteria, micrococci, and bacilli of putrefaction a distinct blue, side by side with the bright red of bacilli of tubercle. For these observations I used a moderately strong watery solution of the methylene blue, having previously stained red with Dr, Heneage Gibbes' magenta liquid, or with a modification of it rather more convenient to prepare and quite as effective. This liquid was made with magenta or fuchsin, the latter being, if anything, the more brilliant. It is prepared by mixing half a drachm of pure aniline with seven drachms of spirits of wine, dissolving ten grains of fuchsin or magenta in this mixture, and adding an equal bulk of distilled water. The crystals are simply put into the bottle, which is then shaken. I have no reason to think that these exact proportions are the best, but they do very well. In this way the contrast may be very nicely shown in sputa; but my test observations were made upon young solid pulmonary tubercle from a spirit preparation, crushed with a little distilled water in an agate mortar, so as to produce a puriform-looking mixture, which was treated as a film in the ordinary way. With the above process, the film was shown to contain only tubercle bacilli stained red and no septic bacteria could be shown by the ordinary stains used for them. The same pounded tubercle was then left for two or three days in a warm room, lightly covered, and then examined by the same process showed blue septic bacteria, microcucci, and bacilli, side by side with the red tubercle bacilli. In this putrefying tubercle ordinary stains for septic bacteria, such as metbyl violet, showed them well, but not the tubercle bacilli. Gentian violet is not, I think, so nice a contrast, and therefore not so desirable for the second stain, as methylene blue, and has in respect of the 
septic bacteria no special advantage so far as I can discover. Ehrlich, in his first paper (May, 1882) recommends blue as the contrast when red is used to stain the tubercle bacillus, and this led me to try the methylene blue among others. It seems to me the best of those which up to the present I have used. Dr. Heneage Gibbes' magenta liquid certainly has with me been much more effective than the original weaker anilin stains recommended by Ehrlich; but if one views the process as a whole, including the action of the acid upon the first stain, it is difficult to escape from the conviction that his process is essentially Ehrlich's improved. After using several acids of various strengths I have adopted, as the most convenient and best, nitric acid, one part, with four parts of water, rather than the one-to-two generally used, and first recommended by Ehrlich. A similar red staining solution may be made with magenta or fuchsin, using ammonia or potash instead of anilun ; but although the bacilli of tubercle may thus be shown, they are neither so certainly nor so strongly stained as by the anilin solution. I find, as Mr. Prideaux does, that the washing in absolute alcohol and drying in air after the second stain may be dispensed with.--I am, Sir, your obedient servant,

Nottingham, Jan. 13th, 1883

W. H. RANSOM.

\section{"PICRIC ACID AND SUGAR TESTING."}

\section{To the Editor of THE LANCET.}

StR,-Dr. Pavy accuses me not only of ignorance of fundamental chemical principles, but also of "confusion in writing," and of introducing into this discussion "complexity and fallacy." Putting aside, therefore, all controversial language, I will simply make a plain statement of facts.

1. The absence of sulphide in a solution of albumen which has undergone prolonged boiling with potash is not due to gradual oxidation of sulphide by air and moisture during the boiling, for the same result is observed when the ebullition is conducted throughout in an atmosphere of care. fully purified hydrogen gas.

2. If the sulphur of the albumen is eliminated at all in the gaseous state during ebullition with potash it is certainly not given off in the form of ammonium sulphide, or any other volatile sulphide; for when albumen and potash are boiled together in an atmosphere of hydrogen carefully purified, and the vapours and gases issuing from the boiling alkaline solution are conducted into a solution of lead, no black precipitate is formed in the lead solution, however long-continued the boiling may be.

In case anyone should be inclined to repeat this experiment with a view to test its accuracy, I may mention that the hydrogen was purified by passing through (l) a solution of corrosive sublimate and (2) a llask containing boiling solution of potash before it entered the flask containing the albumen and potash, which were also kept boiling, and finally the gas was conducted into an alkaline solution of lead hydrate. The lead solution remained clear and colourless throughout the experiment; and on testing the alkaline albumen, after boiling for three-quarters of an hour in the atmosphere of pure hydrogen gas, no indication of sulphide could be observed.

The pure albumen employed by me was made by the method of Wurtz, and at no period during the ebullition of this substance with potash could any evidence be obtained of the presence of sulphide in the cooled liquid, even by the application of the most delicate tests.

I, therefore, having employed every possible precaution not with a view of introducing "complexity and fallacy," but with the object of avoiding otherwise inevitable error, most emphatically repeat my original statement, that no sulphide, either volatile or fixed, is produced when pure albumen is boiled with potash, and I make this statement without the slightest hesitation, in the firm belief that experiment will prove it to be true.

I am, Sir, yours truly,

'King's College, Jan. 20th, 1883.

$$
\text { G. STILLINGFleEt Johnson. }
$$

\section{ANTHRAX}

\section{To the Editor of THE LANCET.}

SrR,-In an annotation in your issue of the 13 th inst. you draw attention to the fact that, contrary to the generally received opinion, the placenta does not al ways constitute an impassable barrier to the passage of the bacilli of anthrax from the blood of pregnant animals to that of the fotus. In corroboration of that statement $I$ may tell you that during the past summer while investigating an outbreak of anthrax in a flock of forty ewes-produced by the carcass of an anthrax sheep buried in the pasture ground the previous summer-I found well-marked anthrax lesions in the fœetuses of three ewes which had succumbed to the affection; and not only this, one or two of the animals aborted and recovered : it was also observed that most of the ewes which had lambed before the symptoms of the disease were shown recovered and did well. This case only confirmed strongly the opinions I had previously entertained in reference to this matter.

I am, Sir, yours truly, Thomas WALLEY,

Edinburgh, Jan. 19th, 1883 Principal, Royal Dick's Veterinary College.

\section{THE ${ }^{-}$HOUNSLOW TRAGEDY.}

\section{To the Editor of THE LANCET.}

SIR,-The jury empanelled to inquire how, and by what means, Dr. Wm. Whitfield Edwardes, late of Bath-road, Hounslow, came by his death, having returned a verdict which, as I have read the evidence, meets the just requirements of the case, I write to express the hope that the profession generally will give its opinion on this sad story. If this view meets with approval, the most practical and beneficial way in which we can express our sympathy with the survivors of Dr. Edwardes' family is to raise a fund for the benefit of his widow and children. I therefore, through your columns, ask the aid of my brethren for this object.

Soho-square, W., Jan. 20th, 1883 I am, Sir, yours truly, JOSEPH ROGERS.

A BRIEF SUMMARY AND DIGEST OF THE WORK OF THE DEVONSHIRE HOSPITAL AND BUXTON BATH CHARITY DURING THE YEAR 1882.

(Communicated by WILLIAM H. RobERTSON, M.D., F.R.C.P., Consulting Physician to the Hospital, and Chairman of the Committee of Management.)

AT the annual meeting of the Committee of Management of the Devonshire Hospital and Buxton Bath Charity, Dr. Lorimer, the resident medical officer, and Mr. Craig, the clinical assistant, presented several tables analysing the work of the hospital during the past year. These tables appear to contain much that may be of general medical interest, and additional similarly suggestive details are in preparation. It may be hoped that these painstaking and capable medical residents will communicate these results to the profession, and possibly one or more of the able members of the acting medical staff will utilise the valuable casebooks of the hospital for the public advantage; but, in the meantime, I venture to ask for space to make what I should be glad to find may be only a preliminary account of the experience derivable from the Buxton Rheumatic Hospital.

During the year 1882 there were 1856 in-patients received. Of these, 1340 were suffering from rheumatism proper, of whom 784 were males and 556 females; 17 were cases of gonorrhceal rheumatism, the whole of whom were males; 138 were cases of rheumatoid arthritis, of whom 12 were males and 126 females; 35 males were cases of gout, of which 12 were complicated with lead-poisoning; 19 were suffering from lead-poisoning apart from gouty complication, of whom 17 were males and 2 females; and 180 of the total patients received were suffering from other diseases, of whom 112 were males and 68 females. Of the 1340 cases of rheumatism proper, 2 males and 2 females were under ten years of age; 52 males and 57 females were from ten to twenty; 145 males and 126 females were from twenty to thirty; 157 males and 101 females were from thirty to forty; 173 males and 95 females were from forty to fifty 128 males and 102 females were from fifty to sixty; 97 males and 59 females were from sixty to seventy; 29 males and 14 females were from seventy to eighty; and 1 male was upwards of eighty years old. The 